\title{
Discussion of Electronic Information Innovative Talents Culture in Forestry Universities
}

\author{
Feng Jiang ${ }^{1, a, *}$ \\ ${ }^{1}$ School of Computer and Information Engineering, Central South University of Forestry and \\ Technology ,Changsha 410004, PR China \\ ajf09mail@163.com \\ ${ }^{*}$ Corresponding author
}

\begin{abstract}
At present the main task of higher education is to improve the quality of talented person training, and cultivate innovative engineering talent.This article analyzes the current situation and the existing problems of electronic information profession students' innovative ability culture in Forestry University,and proposes the innovative ability can obtain through innovative engineering education concepts and teaching methods, build a new personnel training mechanism and modes which carried by colleges and enterprises,reform the curriculum system and teaching content.Furthermore, it is another way to culture innovative talents by training higher-Engineering teachers,constructing scientific evaluation and incentive mechanism.
\end{abstract}

Keywords: Innovative talents, Teaching effect, Teaching reform,Electronic information.

\section{林业类高校所设电子信息类专业创新人才培养的探讨 \\ 蒋峰 $1, a,{ }^{*}$ \\ ${ }^{1}$ 中南林业科技大学计算机与信息工程学院, 长沙, 中国 \\ ajf09mail@163.com \\ "通讯作者}

中文摘要. 提高人才培养质量, 培养创新型 工程人才是高校教育目前面临的重要任务。 文章分析了林业类大学电子信息类专业学 生创新能力培养的现状及存在的问题, 提出 创新能力培养应通过创新工程教育观念、构 建校企联合培养人才的新机制、建立人才培 养新模式、改革课程体系和教学内容、创新 教学方法和实践教学体系、建设高水平工程 型师资队伍、建立科学的评价与激励机制等 途径来实现。
关键词: 创新人才; 教学效果; 教学改革; 电子信息

\section{1. 引言}

随着我国高等教育迈入大众教育时代, 以前行业特色明显的一些高校(如: 农林类、 石油类等) 开始追求专业的全面覆盖, 以吸 引更多的生源, 其中的大部分学校都涉入到 所有的学科领域 (如: 有些学校还开设了体 
育等专业）, 然而, 由于这些行业特色明显 的学校除了其本身的学科优势外, 其他学科 缺乏应有的知识积累, 大多数新涉入的学科 存在教学经验不足, 培养模式陈旧, 学生创 新能力缺乏等问题。文中将从学生的创新能 力培养角度出发, 结合专业人才培养的实际 情况, 对林业类高校所设电子信息类专业工 程技术创新人才的培养进行探究[1-2]。

\section{2. 创新人才培养的意义}

1）国家发展战略的需要

一直以来, 我国将“提高自主创新能力, 建设创新性国家” 视作国家发展的战略核 心。创新能力是提高我国综合国力的关键和 根本所在, 是高校义不容辞的责任。为此, 国家制定了《国家中长期教育改革和发展规 划纲要(2010-2020年)》、《国家中长期人才 发展规划纲要(2010-2020年)》以及《教育部 关于全面提高高等教育质量的若干意见》等 政策来促进、保障创新人才的培养。

2) 改变我国高等教育现状的客观需要

目前，我国高等教育普遍存在重理论、 轻实践; 重分析、轻综合; 重个体, 轻协作; 重传统、轻创新等问题。创新人才的培养将 从根本上打破我国传统人才的培养模式, 为 我国高等教育的发展带来根本性变革。

3）社会发展对创新人才的需求

人类的进步,社会的发展需要人才, 人 才的需求逐步呈现出多样化的趋势, 这对高 等教育的发展提出了更新、更广、更高的要 求。特别是我国工业界的产业转型、升级、 技术创新等都需要大量的创新型人才。因 此, 面向经济建设, 紧跟社会需求, 立足于 大学生创新与实践能力的培养已成为高等 教育中人才培养模式改革的战略核心。

4）学校自身发展以及参与教育国际化 竞争的需要

改革教学模式, 提高学生的综合素质, 拓展学生的就业渠道, 增强学生的创业能力 已成为高校教学改革的新思路。学生创新能 力的加强有助于提高大学教育的核心竞争 力, 有助于产学研的结合, 有助于大学参与 教育的国际化竞争。

\section{3. 林业类高校电子信息类专业人才培养的 现状}

1）缺乏创新的教育理念和先进的教学 模式

通常林业类高校电子信息类专业的创 办时间不长, 缺乏相应学科专业知识的历史 积淀, 因而大部分学校的相关专业都借鉴其 他高校的教学模式, 缺乏自身教育理念和教 学模式的创新。在教育理念和教学方面, 注 重于知识的传授, 轻于学生实践能力的培 养, 学生的创新能力培养往往被忽视, 形成 一种纸上谈兵式的尴玠教学模式。教学中的 主客体发生错位, 学生的被沦为教学的客 体。教学中所有的教学材料 (如: 教学大纲、 教学计划、教案等) 都是从教师自身角度出 发进行编写, 与学生实际情况的需求脱离严 重, 教学过程中教师的主观性、刻板性以及 臆断性占主导地位[3], 学生处于被动的、 消极、盲目的学习状态, 学习的主动性、积 极性不高, 厌学、不学的现象严重, 教学效 果差。

2) 课程结构及设置不合理, 存在一定 的缺陷

林业类高校电子信息类专业的课程结 构及设置基本上借鉴于其他的高校, 课程结 构及设置紧紧围绕专业教学服务, 从而造成 专业教学计划、课程体系设置单一、灵活性 不强, 缺乏复合性和多样性, 与现在学科发 展中多学科交叉、融合的发展趋势相违背。 课程设置中必修环节比重大, 选修环节比重 少 [4]; 课程中的教学内容存在重叠, 课程 开设的衔接较差, 教学质量和教学效果不 好。此外, 课程设置中忽视人文与社会科学 的学习, 学生的视野受到限制, 阻碍了学生 创造力的发展。

3) 实验课程重视程度不够, 实验内容 单一，学生自主性实验内容少

由于林业类高校电子信息类专业的开 设时间不长, 相应的实验课程的教学设备投 入不足, 开设的实验课程比例不高, 实验主 要以简单的验证性实验为主, 实验内容单 一、知识陈旧 [5], 学生自主设计性实验缺 之, 实验教学的本质上还是教师 “帮着走” 的模式, 对学生的创新能力的培养不足。此 外, 实验教学的手段落后, 其教学的目的性 
不明确, 缺乏明确的教学计划, 而且现代教 育技术手段应用不多, 先进的虚拟实验教学 方法引进的程度不够。

4）所设专业与企业之间的合作不够紧 密, 联系不深入, 培养的人才无法满足企业 的需求

林业类高校电子信息类专业由于开设 时间不长, 与开设相同专业的传统老牌学校 相比, 在社会上的影响力不够, 社会认可度 缺乏, 因而相关企业寻求与学校合作的热情 不高, 企业缺乏合作的主动性和积极性, 进 而造成林业类高校电子信息类专业的人才 培养与企业需求之间的脱节, 使相关专业的 人才无法满足企业的需求, 从而反过来又影 响企业与学校的联系与合作, 陷入恶性循环 中。

5）缺乏高水平、具有较强工程实践能 力的师资队伍

林业类高校电子信息类专业由于开设 时间不长, 还没有在社会上形成一定的影响 力, 再加上高校教师待遇偏低, 有工程经历 的优秀人才不愿意从事育人工作, 缺乏对优 秀人才的吸引力; 而且由于是该类学校的新 型专业, 学校的扶持力度不够, 所制定的政 策缺乏一定的激励机制, 使优秀师资培养和 引进难道较大, 师资的整体水平不高。此外, 林业类高校电子信息类专业的企业影响力 不够, 很难与相关企业建立长期的合作, 双 师型[6]教师缺乏。

\section{4. 林业类高校电子信息类创新人才培养的 具体途径}

为改变林业类高校电子信息类专业人 才培养的现状, 提高该类专业学生的创新能 力, 文中提出了以下的实施方案。

1）创新人才[7-9]培养观念

林业类高校电子信息类专业培养的是 工程应用型技术人才, 其培养方式应从传授 理论知识为主转变为学生工程实践能力的 培养, 改变教师教学中的主导地位, 着力突 出学生学习过程中的主体作用, 突出学生学 习的积极性和主观能动性。教师在教学过程 中, 应逐步将工程实践与理论教学相结合, 让学生在学习的过程中能知道学有所用、学 能所用, 从而真正的激发学生的学习热情。
在人才培养中, 有意识的注重学生的创新能 力培养, 教学中多采用启发式的教学方式, 最大程度上调动学生的创新思维模式。

2）构建创新人才的培养体系

在课程设置上, 建立多学科、多方向的 选修课程组, 提高学修课程比例, 鼓励学生 根据自身的学习兴趣自主选课。在实验教学 方面, 加大仪器设备等硬件平台的建设, 更 新实验教学手段, 压缩验证性实验的比例, 增加设计性实验、综合性实验的比重, 使实 验教学真正做到为培养学生的实践、创新能 力服务。

在考核方式方面, 增加课程论文、专题 讲座等评价环节, 逐步改变我国长久形成的 应试教育评价体系, 充分发挥学生的自主力 和创造力。

3）努力构建校企联合人才培养机制

人才培养的最终目的是满足企业的需 求, 为改变电子信息类专业与相关企业联系 不足的局面, 学校设置了专项资金, 用于加 强与企业的合作。破除面子观念, 从被动等 待企业联系的方式转变为主动出击, 积极走 访用人单位, 征询企业对人才的需求信息, 共同构建校企联合人才培养机制。高校与企 业共同设计培养目标[10], 制定培养计划, 聘请企业工程技术人员共同参与人才的培 养工作, 使培养出的人才具有较强的工程实 践能力, 更好地满足企业的需求。

建立校企联合培养的新模式[11-16], 将 学生的学习阶段划分为校内学习和企业实 习两个阶段, 根据人才培养的具体需求, 灵 活的采用 “ $3+1$ ” 、“ $2+0.5+1+0.5$ ” 等多种 学习模式, 实现校企的联合培养。

4）建立长效的师资队伍培养机制

林业类高校电子信息类创新人才培养 的关键在于有一支高水平的、创新能力强的 师资队伍。为提高师资队伍水平, 可以通过 以下几个方面来实现。

(1) 自我学习, 自我提高。鼓励教师 深入工厂、企业参加项目开发, 使教师由单 一的教学型向教学、科研、生产实践一体化 的 “双师型” 目标转变。特别是对于新教师, 规定其必须进实验室工作一年, 负责实验教 学指导、设备管理及维修工作。 
（2）从高校接收博士研究生以上学历 和引进副教授及以上职称教师, 不断提高整 个师资队伍的学历和职称结构, 形成较为合 理的学缘结构及师资配置。

(3) 聘请部分企事业单位的技术骨干、 项目开发人员担任兼职教师。

（4）加大对外交流。每年选派1～2名 教师到高校进修、培训或做访问学者等, 以 提高学历和教育理论水平, 学习新理论、新 技术等。

(5) 建立教师职称评审、晋级、转岗 等新机制。将人才培养的质量作为教师考核 的关键性指标, 谈化现有的以科研、论文为 主的评价体系, 允许不再适合教学的教师转 岗聘用。

（6）大幅提高教师的薪资待遇和课时 酬金, 增强教师的荣誉感和责任感, 充分调 动教师学习、进步的热情。

\section{5. 结束语}

随着国家 “以信息化带动工业化, 实现 跨越式发展” 的发展战略的制定, 信息产业 列为未来 5 年率先发展的七大战略性新兴产 业, 信息产业将作为我国产业升级、转型的 主力军。信息产业的发展关键要靠高素质的 信息类创新人才。

对于林业类高校电子信息类专业而言, 我国信息产业的发展为专业的发展提供了 一个良好的机遇, 但创新人才的培养是一个 长期的、复杂的系统工程, 是林业类高校必 须长期面临的重大课题和任务。林业类高校 电子信息类专业在培养学生创新能力的过 程中应将创新的理念贯穿于教育的始终, 融 传授知识、素质培养、创新教育为一体, 建 立有效培养学生创新能力的新的机制和完 善的培养体系, 这对于推进我国高等教育的 改革和发展、培养创新型工程技术人才、建 立现代化创新型的工业强国具有重大的意 义。

\section{致谢}

本文为湖南省普通高等学校教学改革 研究项目《电子信息类卓越工程应用型人才 培养的体系构建研究》以及中南林业科技大
学教学改革研究项目《电子信息工程专业认 证与人才培养模式的优化研究》的阶段性成 果之一。

\section{References}

[1] James R. Eifert, The predominantly undergraduate institution: Its place in engineering education in the united states, Proceedings of International Symposium on Higher Engineering Education, pp. 294-300, 1990.

[2] Barry J. Farbrother,Training tomorrow's engineers-some experiences at an independent college, Proceedings of International Symposium on Higher Engineering Education, pp. 315-323, 1990.

[3] Pingyan Huang and Hanying Zhu, The cultivation of college students ' innovation ability,Course Education Research, vol.16, pp. 235,2013.

[4] Zhao Xiaowen and Lin Jian,An international comparative study of engineering talents training models, Research in Higher Education of Engineering, vol.2, pp. 33-41,2011.

[5] Zhang Xiao-guang, The practice teaching reform measures of the major of electronic information engineering, Vocational and Technical Education, vol.11, pp. 26-27, 2008.

[6] Wang Hai-mei,Quan Wei-qiang,and Wang Xing-jun, The exploration and reform of the major of electric information engineering in our institute, Journal of Shanxi Institute of Technology, vol.18, pp. 35-37, 2008.

[7] Zhu Hong,An exploration of innovative talent producing mode in colleges and universities, Journal of Higher Education Management, vol.2, pp. 6-11, 2008.

[8] Liu junrong, Thoughts on constructing training mode of innovative talents in universities,Journal of Hubei University 
of Economics(Humanities and Social Sciences), vol.5, pp. 80-81, 2008.

[9] Shi Juhua, Construction and implementation of training mechanism on college students creative ability, Journal of Chongqing Institute of Technology(Social Science), vol.23, pp. 179-181, 2009.

[10]Wang Wan-zhen and Chai Wen-yan, The research on educational systems of the electric information and engineer for undergraduates,Journal of Beijing City University, vol.4, pp. 14-18, 2006.

[11]Gong Ke, Changing conception, bold experiments to establish an outstanding engineering education mode of China, China Higher Education, vol.18, pp. 10-12, 2010.

[12] Shuchuan Peng and Benjun Zhou, Study on course teaching system construction OF environment engineering based on the excellent engineer training, The 3rd International Annual Conference on Teaching Management and Curriculum Construction, pp. 229-232, 2012.
[13]Wang Hancheng and Jiang Lejun.Enlightening of home and international college-enterprise cooperation on "program of educating and training excellent engineers" in China, Journal of Huaihai Institute of Technology(Social Science Edition), vol.8, pp. 14-16, 2010.

[14]Wang Wenhu, CDIO-oriented teaching reform of cartography teaching conception--The rational thought of teaching reform based on the excellence engineers cultivatin, Science of Surveying and Mapping, vol.3, pp. 247-249, 2011.

[15]Lin Jian,Essence of excellence in engineering education innovation-oriented talents training mode of Engineering, China Higher Education, vol.3, pp. 19-21, 2011.

[16]Lin Jian, On the professional training program of "A plan for educating and training outstanding engineers", Tsinghua Journal of Education, vol.32, pp. 47-55, 2011. 